\title{
MODALIDADES EDUCATIVAS DE LA RADIO EN LA ERA DIGITAL
}

\author{
Juan José Perona Páez \\ Mariluz Barbeito Veloso \\ Profesores de Comunicación Audiovisual y Publicidad. Universidad \\ Autónoma de Barcelona (UAB).
}

\section{Resumen}

La radio presenta múltiples posibilidades de explotación dentro y fuera del aula, consagrándose como una potente herramienta complementaria y de refuerzo de la enseñanza y el aprendizaje. Las alternativas que ofrece el medio van mucho más allá del potencial instructivo y formativo que históricamente se le ha conferido, al tiempo que, gracias a los avances tecnológicos, crecen exponencialmente. Este artículo se aproxima a las diferentes modalidades educativas que, en plena era digital, brinda la radio.

\section{Palabras clave}

Radio-Lenguaje audiovisual-Educación-Nuevas tecnologías

\section{Abstract}

The radio presents multiple possibilities of exploitation inside and out of the classroom, devoting itself as a powerful complementary tool and of reinforcement of the education and the learning. The alternatives that the way offers go far beyond of the instructive and formative potential that historically one has awarded him, at the time that, thanks to the technological advances, they 
grow. This article comes closer the different educational modalities that, in full digital age, the radio offers.

\section{Key words}

Radio-Audio-visual Language -Education-New tecnologies 


\section{Introducción}

Los medios de comunicación social son instrumentos de servicio público a los que tradicionalmente se les ha venido confiriendo el nada despreciable poder de Informar, Entretener y Educar ${ }^{1}$. En plena sociedad de la Información, las líneas que separan estas tres funciones en los países más desarrollados están cada día más desdibujadas -la hibridación genérica a la que asistimos desde hace ya más de una década, unida a la consolidación de nuevas formas de transmisión de los contenidos como Internet corroboran esta tendencia-, pero todavía pervive una cierta obstinación por clasificar los productos que los medios ponen al servicio de los ciudadanos según las dosis de información, entretenimiento o educación que contienen. Es más, aún hoy se sostiene la hipótesis de que cualquier mensaje mediático es, por naturaleza, susceptible de enseñar.

En cualquier caso, es bien cierto que la prensa, la radio, la televisión o el cine -y más recientemente la $\operatorname{Red}^{2}$-, han sido y siguen siendo herramientas en las que, en mayor o menor medida, la escuela y otras instituciones no han dudado en apoyarse para desarrollar ciertas fases de la enseñanza y del aprendizaje. En algunas ocasiones, se revelan de gran utilidad para estimular la reflexión y la crítica entre el alumnado; en otras, los lenguajes con los que trabajan los medios, especialmente los audiovisuales, dinamizan las sesiones académicas y facilitan la comprensión; en otras muchas, los soportes impresos son un buen utillaje para ejercitar la lectura entre los más jóvenes; y en otras, incluso, los centros escolares han llegado a dotarse de medios propios para aunar todo ese potencial y activar la participación directa de estudiantes y profesores en la producción de materiales de gran valor pedagógico.

\footnotetext{
${ }^{1}$ Desde una perspectiva más amplia, el sociólogo Alberto Moncada (2000) advierte que la educación, la información y el entretenimiento son en la actualidad tres grandes industrias en expansión, especialmente en los países más desarrollados.

2 "Internet es un instrumento cultural para abrirse hacia el mundo. En algunos colegios de barrios marginales, alumnos que jamás han pisado un museo pueden explorar imágenes y textos suministrados por el servidor (...) Internet se ha convertido en una pieza maestra de la modernización del sistema de enseñanza". Archambault, Jean-Pierre (1998): "Internet en la escuela". En Ramonet, Ignacio (ed.): Internet, el mundo que llega. Los nuevos caminos de la comunicación. Alianza Editorial. Madrid. Páginas 235 y 236.
} 
En el terreno de la educación, la radio, como bien demuestran las experiencias que se han llevado a cabo en distintos países del mundo, presenta amplias posibilidades de explotación fuera y dentro del aula. En el primero de los casos, se consagra como un medio de enseñanza a distancia que, al igual que la televisión, ha servido y sigue sirviendo para instruir a muchas personas, especialmente en los lugares menos favorecidos (Tiffin, J. y Rajasinghma, L., 1997). Así, por ejemplo, desde esta perspectiva "los programas enfocados a la educación nacen a partir del índice de deserción o de no asistencia al sistema escolarizado formal, debido a que las instituciones escolares se encontraban a distancias inaccesibles en algunas poblaciones. La radio, como un medio alternativo económicamente accesible para tenerse en los hogares, fue el espacio alternativo para la educación (...), alfabetizando los rincones más insospechados, con la difusión de programas grabados de matemáticas, español, y desarrollo en las comunidades, todo ello coordinado por un locutor que entregaba reportes del proceso" (Arteaga, C., 2004).

En el segundo de los casos, la radio puede tener múltiples aplicaciones: desde despertar la imaginación entre los niños y las niñas, hasta convertirse en un formidable instrumento para mejorar la expresión oral y la capacidad creativa entre el estudiantado, sin olvidar que muchos de sus productos contribuyen a ampliar el conocimiento sobre el entorno político, económico, social, cultural y natural que envuelve a los/as alumnos/as $\mathrm{y}$, consecuentemente, a mejorar su relación con todo aquello que les rodea. Sacar más o menos provecho a las oportunidades que brinda el medio dependerá, lógicamente, del uso que de él se haga.

Inmediatez, heterogeneidad de la audiencia, fugacidad, credibilidad..., son características estrechamente ligadas a la radio, como también lo es el bajo coste que, comparado con la televisión o la edición impresa, supone la producción de espacios radiofónicos. La radio, ciertamente, es barata. Esta última circunstancia ha favorecido que, en algunas de aquellas escuelas en las que se ha introducido el medio, se haya apostado incluso por la creación de una emisora propia. De hecho, la radio en la escuela abre dos grandes vías de explotación: Por una parte, creando productos cuyo soporte sea 
el sonoro, incluso aunque no se disponga de un estudio de radio. Por otra parte, oyendo y analizando programas escogidos previamente, prestando atención a la forma y al contenido. En otro apartado de este artículo se ahondará sobre estas cuestiones, pero como ya se puso de manifiesto en otra ocasión (Perona, 2001), en los centros en los que se ha puesto en marcha una emisora, sus responsables han constatado su enorme validez para, entre otras cosas:

\section{Fomentar y reforzar el trabajo en equipo;}

2. Potenciar la iniciativa y la capacidad creadora del profesorado involucrado en el proyecto;

3. Mejorar la expresión oral y escrita entre los estudiantes, así como la utilización de los signos de puntuación;

4. Aumentar de forma significativa el uso de la biblioteca;

5. Favorecer la integración del alumno, aproximándolo a su entorno;

6. Desarrollar una nueva manera de educar: activa, abierta a la vida, democrática, crítica y solidaria; $y$

7. Dinamizar la comunicación entre la comunidad escolar.

Se trata, en definitiva, de diferentes desarrollos de la educación en medios, es decir, de "enseñar a comprender, analizar y usar los medios de comunicación (...) de transformar la comunicación audiovisual en materia de estudio" (Oliva, M., 2006: 30), pero también de educar a través de los medios (educación con medios).

Junto con las diferentes experiencias a las que hemos aludido, la apuesta de algunas (pocas) emisoras de radio por incluir en sus parrillas programas destinados a la población infantil es otra manera de explotar las posibilidades educativas que brinda un medio como el que nos ocupa. Estos programas, con más o menos altibajos en cuanto a presencia en las ondas se refiere, han sido puestos en antena con el objetivo primordial de entretener al público para el que habían sido concebidos, aunque nunca han faltado contenidos con un alto valor pedagógico. La escuela, globalmente entendida, se ha 
convertido en ocasiones en el centro de debates, tertulias, y reportajes radiofónicos, aunque no ha sido objeto de espacios específicos.

No obstante, la progresiva homogeneización a la que ha tendido la oferta radiofónica española y el marcado conservadurismo programático que se ha extendido entre los grandes operadores (Gutiérrez y Huertas, 2003, Perona, J.J., 1997), no ha propiciado, ni mucho menos, el desarrollo de este tipo de espacios en nuestro país, aunque como luego se verá ciertas emisoras autonómicas no han dudado en potenciarlos.

Así, en el conjunto de la radio generalista, es decir, aquella que basa su parrilla en el llamado modelo convencional -variedad de géneros programáticos dirigidos a públicos diversos, segmentados según las diferentes franjas horarias-, y que alcanza importantes índices de penetración entre la población ${ }^{3}$, la Información y el Entretenimiento acaparan aproximadamente el $70 \%$ de la oferta, mientras que el Deporte ocupa algo más del $10 \%$. El porcentaje restante se consagra a la Música y a los espacios de Participación, y en menor medida a la Cultura, la Educación, la Religión y otros géneros tan minoritarios como la Ficción, que sólo tiene una presencia esporádica y testimonial en las emisoras de titularidad pública. Esta uniformidad programática, cuya evidencia es aún mayor si tenemos en cuenta que las distintas redes optan por emitir los mismos contenidos a las mismas horas, afecta a la amplia mayoría de operadores, incluso a aquellos que se han ido gestando en los últimos años. En relación con las redes especializadas, el aumento del número de estaciones al que asistimos en la década de los 90 no ha propiciado, tampoco, un enriquecimiento en cuanto a diversidad programática se refiere.

\section{Sobre el concepto de radio educativa}

Pese a lo comentado hasta este momento, hablar de radio educativa, o de la existencia de emisoras educativas, no parece ser lo más apropiado, puesto que, en sintonía con apreciaciones como las de Merayo, "bajo esta denominación se agrupan modalidades

\footnotetext{
${ }^{3} \mathrm{Si}$ atendemos a los datos más recientes del EGM de que disponíamos mientras redactábamos este escrito, es decir, los relativos a la segunda oleada de 2006, la radio es seguida diariamente por el 55,53\% de la población, y sólo es superada por la televisión, que cuenta con una audiencia diaria de casi el $89 \%$. El consumo medio de radio al día se sitúa en 112 minutos repartidos casi equitativamente entre la radio generalista y la temática: 54 minutos para la primera y 53 para la segunda
} 
radiofónicas muy diferentes: instructiva, comunitaria, popular, formativa...Todas ellas eso sí-, parecen compartir un rasgo común: intentan alcanzar objetivos no comerciales y se orientan especial y directamente hacia una finalidad de carácter social" (Merayo, 2000). Por esta razón, resulta mucho más acertado referirse a modalidades de radio educativa, que son las que en realidad posibilitan las distintas acepciones anteriormente referenciadas. Lógicamente, esta argumentación niega la existencia de emisoras educativas, pero no así la de estaciones de diversa índole -además de las citadas por Merayo, podrían incluirse también las escolares-, o la de programas cuya principal finalidad es educar con contenidos específicos. Tampoco rechaza, ni mucho menos, el concepto de radio con fines educativos.

Por otra parte, en el marco de las modalidades de radio educativa encajan todo tipo de acciones que, por ejemplo, las administraciones públicas, aprovechando las posibilidades de la convergencia tecnológica en la era digital, vienen desarrollando para fomentar la educación en comunicación audiovisual. En el caso concreto de la radio, en España destacan, por ejemplo, Media Radio, un recurso online del Centro Nacional de Comunicación e Información Educativa (CNICE), o el proyecto Xtec Ràdio, impulsado por el Departament d'Educació de la Generalitat de Catalunya.

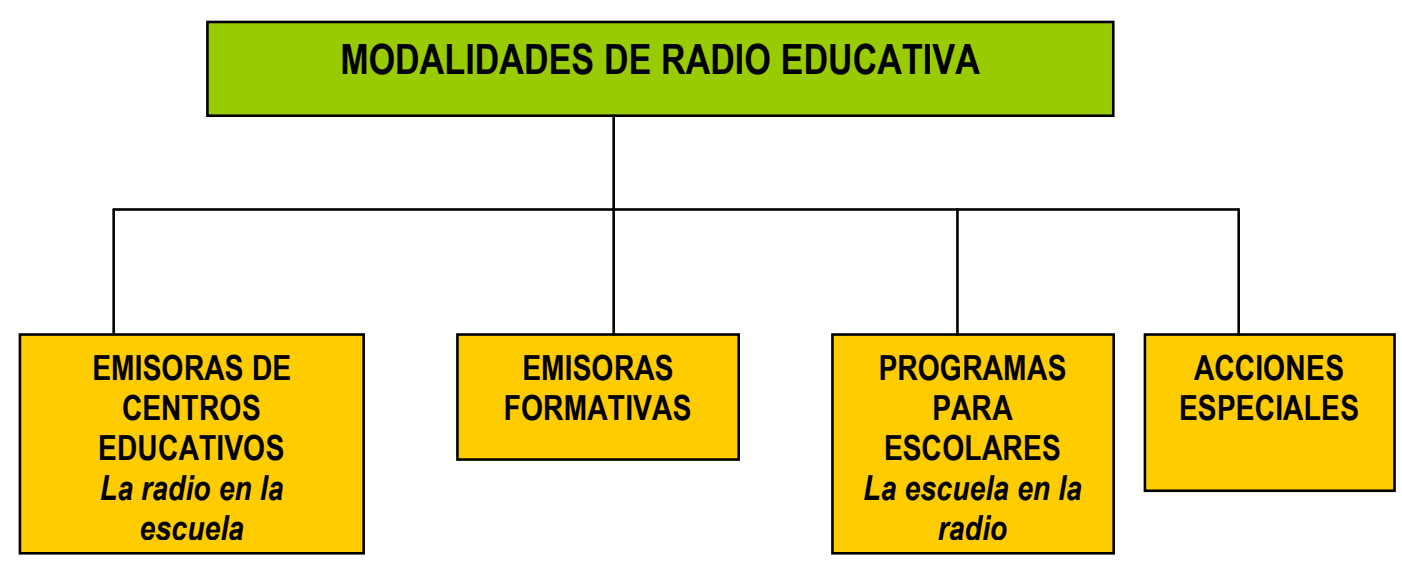


Una vez esbozadas las diferentes modalidades educativas de la radio, es momento ahora de estudiar las peculiaridades que presenta cada una de ellas, y lo que es más importante, explorar sus distintas formas de manifestación en nuestro país.

\section{Emisoras de centros educativos, un fenómeno en auge}

Los centros educativos españoles que actualmente cuentan con una emisora de radio se reparten por toda la geografía peninsular, aunque su presencia es sensiblemente mayor en aquellas comunidades autónomas en las que, tras el fin de la dictadura franquista, se fraguaron auténticos ecosistemas comunicativos locales. En efecto, el arribo de la democracia y la particular distribución territorial y administrativa del Estado que con ella se configuró, condujo a una reorganización del panorama comunicativo que desembocó, como es sabido, en el nacimiento (o la reaparición) de medios audiovisuales de proximidad. Así, por ejemplo, los operadores autonómicos se crearon para ser los vehiculadores de las particularidades de las diferentes comunidades pluriculturales que conforman España (Barbeito, M.L., 1999), lo que lleva a pensar que los principios que vertebraron lo local son los mismos que encauzaron los de carácter autonómico en cuanto a políticas comunicativas se refiere: promoción cultural, defensa de la lengua propia y dinamización socio-económica de una determinada comunidad.

Junto con las estaciones de proximidad públicas (autonómicas y municipales), en el terreno de lo local surgieron también emisoras independientes de distinto calibre, impulsadas por colectivos tan diversos como asociaciones de vecinos, grupos de amigos de la radio, entidades culturales y, también, centros escolares. En algunos casos, sobre todo en pequeñas poblaciones con escaso número de habitantes, estas últimas llegaron a convertirse, incluso, en estaciones radiofónicas que servían a toda la localidad, puesto que eran las únicas que existían. "El nacimiento de la radio escolar suele tener rasgos comunes: un profesor aficionado a la radio (por lo menos como oyente), un profesor o un padre radioaficionado o con algunas inquietudes y conocimientos técnicos, la continuidad de una revista siempre limitada, reiterativa y pendiente de la voluntad de 
muy pocos, un taller esporádico en una escuela de verano o semana cultural, una actividad extraescolar de cara al barrio o al pueblo, un grupo de jóvenes que ponen en marcha una programación voluntarista como respuesta a su incapacidad de acceso a los centros de decisión y de expresión"4.

A mediados de la década de los 80, en la mayoría de las comunidades españolas existía alguna experiencia de radio escolar, aunque la diversidad en cuanto a uso del medio y estructura programática era la tónica dominante. De hecho, no todos los centros disponían de los mismos recursos, ni tampoco en todos ellos los profesores implicados en los proyectos poseían los mismos conocimientos sobre el medio. Por otra parte, la estructura del sistema educativo y los diseños curriculares de entonces entorpecían la introducción de la radio en la escuela y su desarrollo, puesto que un buen número de educadores no veían con buenos ojos las iniciativas de introducir el medio en sus centros. Pese a estas dificultades, colegios como el C.P. Ramón y Cajal, en Pina de Ebro (Zaragoza), el C.P. La Peineta, en Puerto Sagunto (Valencia), el C.P. La Gloria, en Vélez (Málaga), el C.P. Santo Cristo de la Veracruz, en Consuegra (Toledo), el C.P. Del Paso, en El Paso, La Palma (Tenerife), el C.P. Serafico, en Elda (Alicante), el C.P. Font Freda, en Montcada y Reixac (Barcelona), e Institutos de Bachillerato como el Juan Antonio Castro, en Talavera de la Reina (Toledo), el de "A Xunqueira", en Pontevedra, o el de Astrabudua, en Erandio (Vizcaya), disponían, entre otros, de radio escolar (Gutiérrez, M., 1986).

A comienzos de la década de los 90, coincidiendo con una clara expansión de radios locales en todo el Estado, las emisoras escolares también se extienden, hasta el punto de que en mayo de 1991 se celebra en la localidad gaditana de Olvera un Encuentro de Radios Escolares. Allí se constata que sólo en la comunidad autónoma de Andalucía funcionan cerca de 60 redes, al tiempo que se detecta una importante implantación del fenómeno en otras zonas como Cataluña, Galicia, Asturias y el País Vasco. En la actualidad, todavía perviven algunas de aquellas emisoras, aunque un buen número han desaparecido o se han transformado en estaciones dependientes de los Ayuntamientos

${ }^{4}$ González, Ferran (1991): "En el dial de mi pupitre". Ponencia presentada en Jornadas Pedagógicas: Radio Escolar. Olvera 91 (Cádiz). 16, 17 y 18 de mayo. 
(municipales). No obstante, a lo largo de los últimos años han surgido nuevos operadores escolares que, además, no han dudado en difundir a través de Internet sus producciones $^{5}$.

Junto con estas emisoras, en España se tiene constancia de la existencia de otras experiencias radiofónicas gracias a los espacios que algunas redes convencionales cedían gratuitamente a los centros (Radio Popular de Granada, donde se emitía el programa Semilla Juvenil; Radio Cadena Española en Las Palmas de Gran Canaria, con el espacio Brújula; Ràdio Reus (Ser), con L'escola a la ràdió; o Radiocadena Española en Monforte de Lemos (Lugo), desde donde se podía sintonizar el espacio Espinilla Rebelde. Por otra parte, el panorama se completaba con emisiones como las de la histórica Radio Ecca, una estación formativa que todavía hoy pervive y que comenzó su andadura escolar el 15 de febrero de 1965 en la isla de Gran Canaria, día en que se transmite la primera clase a distancia para personas adultas.

Uno de los denominadores comunes de las radios escolares que en su día funcionaron en nuestro país, y el de aquellas otras que aún lo siguen haciendo, es su reducida franja de emisión y el hecho de que ésta se lleve a cabo fuera del horario escolar (es decir, como actividad extraescolar), aunque buena parte de los productos que conforman la programación se elaboran en horas de clase. María Gutiérrez (1998) advierte que la radio como actividad extraescolar es una de las fórmulas más usuales de utilizar el medio radiofónico en los centros, aunque también se explotan otras posibilidades, como el taller de radio o implicando el medio en los programas escolares, con emisión de contenidos estrechamente ligados a diferentes asignaturas (soporte didáctico).

El análisis de este tipo de emisoras permite observar, igualmente, una clara coincidencia en cuanto a objetivos y resultados en aquellos centros en los que se ha introducido la radio, con parrillas programáticas que suelen estar compuestas de espacios adaptados a

\footnotetext{
${ }^{5}$ En el caso de Cataluña, por ejemplo, el número de emisoras escolares no ha parado de crecer con el advenimiento de Internet. Para tener una idea más clara de la dimensión de este fenómeno, el lector puede dirigirse, entre otras, a http://www.xtec.es/audiovisuals/mediatic/radio.htm.
} 
cada etapa formativa y con contenidos integrados especialmente en las áreas de Lengua, Conocimiento del Medio y Música. Recitales de poesía, cuenta-cuentos, adivinazas, trabalenguas, recetas de cocina, entrevistas a personajes locales, reportajes con motivo de celebraciones tradicionales -Navidad, Carnaval, etc.-, o comentarios sobre la actualidad, son espacios que habitualmente conforman la oferta de estos operadores. Por otra parte, los centros con emisora escolar suelen implicar a la totalidad de los alumnos, por lo que las actividades radiofónicas son motivo de planificación, seguimiento y evaluación.

Junto con la modalidad educativa radiofónica que acabamos de explicar, en nuestro país conviven un buen número de estaciones que han ido aflorando en distintos centros de educación superior. Estos centros tampoco han dudado en aprovechar las posibilidades que brinda la Red como plataforma de difusión, tanto de productos radiofónicos en sentido estricto como de otros contenidos complementarios.

Una de las principales características que presentan estas emisoras es su programación mosaico, con una oferta netamente diversificada compuesta por numerosos espacios en los que tienen cabida todo tipo de géneros y temas ${ }^{6}$. Un buen ejemplo de lo que aquí decimos lo encontramos en la parrilla de Radio Universitaria de León, una estación en la que en la actualidad pueden sintonizarse espacios sobre "viajes, rock, pop, arte contemporáneo, información universitaria, cine, heavy, sexo, cocina, misterio, salud, marketing, cultura, deporte, hardcore, tendencias, blues, mestizaje, ciencia, jazz..."(http://www3.unileon.es/ondas/radio.html).

Las universitarias son redes que, entre otras cosas, fomentan la radio-creación y se consagran como una verdadera alternativa a los contenidos imperantes en la radio generalista, donde se suceden grandes bloques de Información y Entretenimiento y, como ya advertíamos, apenas tienen cabida otros macrogéneros. Son, igualmente, una

\footnotetext{
${ }^{6}$ En una investigación sobre las emisoras universitarias llevada a cabo en 2004 por los autores de este escrito, se observó, por ejemplo, cómo mientras la Cadena Ser presentaba una parrilla diaria compuesta por 12 programas diferentes más tres desconexiones locales, la oferta de Radio Universitaria de León la conformaban 51 espacios distintos más 7 desconexiones locales con Radio 5. Por su parte, en Radio Autónoma de Madrid se contabilizaban hasta 46 espacios distintos.
} 
clara alternativa a aquellos otros contenidos que protagonizan la oferta especializada, en la que la música, y especialmente el formato Contemporary hit radio, sigue siendo la fórmula más explotada.

A principios de 2007, en el directorio de la Asociación de Televisión Iberoamericana (ATEI) se contabilizaban hasta nueve experiencias de este tipo en España, las cuales quedan recogidas en la siguiente tabla:

Estaciones de radio educativa y cultural en España. (Directorio ATEI 2007)

\section{EMISORA}

Radio Campus

Radio Universidad

La Radio de la UNED

UPV Radio

Radio Autónoma

Villaviciosa Radio

WorldWide Radio

Radio Universitaria

Radio Rua

*Aunque aparece en este directorio, dadas sus especiales características se trata de una emisora formativa, y así es considerada en este artículo.

Fuente: Asociación de Televisión Iberoamericana (ATEI). http://www.ateiamerica.com. Fecha de consulta: 13-04-2007.

No obstante, tenemos constancia de que otras Universidades de nuestro país disponen también de estaciones radiofónicas, como la Universitat Jaume I de Castellón (Vox Uji Ràdio, http://www.radio.uji.es/), o la Universitat Pompeu Fabra (UPF Ràdio), que cuenta con una emisora vía Internet (http://www.upf.edu/cms/cms/upfradio/). En el proyecto de la UPF colabora ICat fm, una emisora recientemente creada por la Corporació Catalana de Ràdio i Televisió (CCRTV) que emite exclusivamente a través de la Red. Por otra parte, algunos centros de educación superior que todavía no tienen radio propia participan en la elaboración de programas radiofónicos universitarios. Es el caso, por ejemplo, de los estudiantes de la Facultad de Ciencias de la Comunicación de la Universitat Autònoma de Barcelona (UAB), que semanalmente producen el espacio 
Fora d'Hores, el cual puede ser escuchado a través de la sintonía de RNE-Ràdio 4 en la madrugada del domingo al lunes, entre las $01.00 \mathrm{~h}$. y las $02.00 \mathrm{~h}$.

\section{Emisoras formativas: docencia en clave radiofónica}

A diferencia de la modalidad educativa radiofónica vista hasta este momento, estas emisoras presentan una estructura programática presidida por espacios de carácter estrictamente docente, por lo que su espíritu es claramente formativo. En España, los máximos exponentes de esta modalidad se encuentran en la ya mencionada Radio Ecca y en La Radio de la UNED.

El primero de estos operadores, que en la actualidad se define como la Emisora Cultural de Canarias y que cuenta con una trayectoria de más de 40 años, se caracteriza por ofrecer una programación docente propia, destinada a cualquier oyente que sintonice con ella, tanto en FM como en AM. Se trata de una experiencia que combina diferentes cursos de formación a distancia, con música de actualidad, "como compensación a la gran cantidad de palabra” que impregna sus espacios educativos. En el año académico 2006/07, esta emisora, que cubre la práctica totalidad del archipiélago canario, seguía haciendo una fuerte apuesta por la enseñanza de las lenguas (inglés, alemán y francés), además de incluir en su parrilla diferentes clases de cultura popular y de formación básica. De hecho, Radio Ecca (http://www.radioecca.org) presenta una amplia oferta, en la que se pueden encontrar cursos de formación básica (alfabetización, cultura popular, formación en lengua, ortografia, etc, y graduado en Educación Secundaria), Bachillerato, Aula Abierta (economía y empresa, formación del profesorado, idiomas, nuevas tecnologías, intervención psicosocial, medioambiente, ocio y tiempo libre, y salud), y Formación Profesional (ocupacional y continua).

Modelos similares al de Ecca gozan de una importante implantación en otros países europeos, sobre todo en los estados nórdicos, donde algunas emisoras vienen destinando parte de su tiempo a actividades formativas. En este sentido, resulta especialmente 
interesante el caso de la estación pública sueca, la $U T B$, que a diario incluye varios cursos de lenguas extranjeras, entre las que se encuentra también el español. En esta red, los programas docentes combinan música y voz, ya que según sus responsables, se trata de estimular a los estudiantes, de despertar su imaginación y de ubicarlos, a través de la magia de la radio, en el país en el que se habla la lengua objeto del curso. En las escuelas, las emisiones se trabajan con un cuaderno de apoyo y, antes de oír el programa -los centros reciben con antelación los productos que se van a radiar, con la indicación del día y la hora en que serán transmitidos-, se lee un texto que alude explícitamente a lo que posteriormente van a escuchar los alumnos. Concluida la audición, se realizan distintos ejercicios que aparecen en el cuaderno al que antes nos referíamos.

Por su parte, la radio de la Universidad Nacional de Educación a Distancia (http://www.uned.es/cemav/radio.htm), cuyos programas se emiten a través de RNERadio 3, presenta una parrilla compuesta por espacios formativos pertenecientes a las cuatro grandes áreas de los estudios universitarios: Ciencias de la Salud, Ciencias Experimentales y Tecnologías, Ciencias Sociales y Ciencias Humanas, como puede apreciarse en su oferta correspondiente al curso 2006/2007.

Parrilla de La Radio de la UNED para el curso 2006/07 


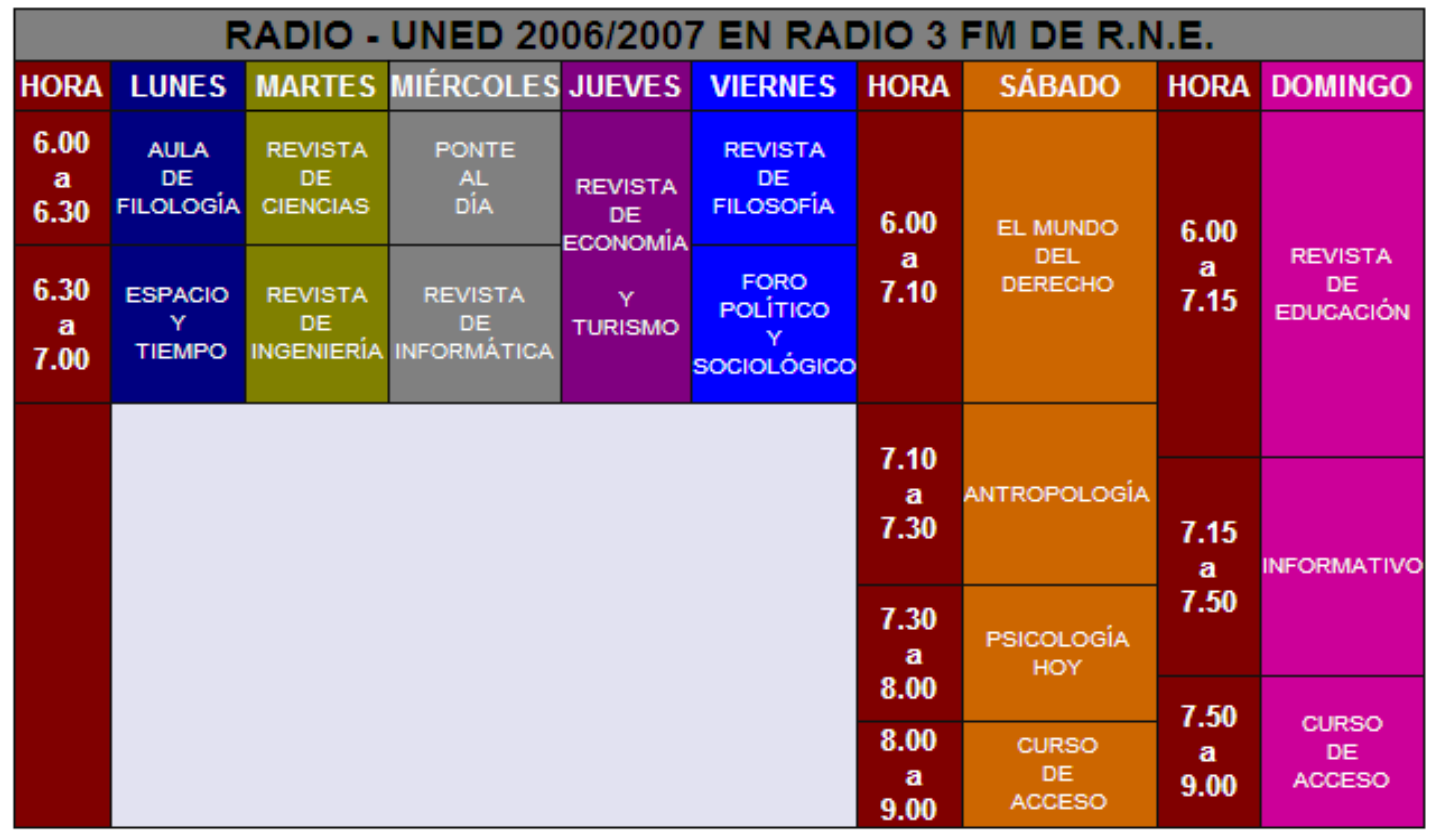

Fuente: http://www.uned.es/cemav/radio.htm\#PARRILLA. Fecha de consulta: 14-04-2007.

Tal y como reza en su carta de presentación, "la Universidad Nacional de Educación a Distancia, fiel a sus Estatutos y al importante compromiso social que ha contraído, incorporó desde sus principios a la radio como un medio idóneo para actualizar y transmitir sus enseñanzas universitarias a distancia. Desde sus comienzos, hace ya más de 25 años, ha trabajado para conseguir una radio que fuese útil para sus alumnos y que, al mismo tiempo, sirviera para hacer llegar la cultura a todas aquellas personas que, aún no perteneciendo a su nutrido alumnado, pudieran estar interesadas en ampliar y perfeccionar sus conocimientos. Los contenidos de la programación, seleccionados y elaborados por profesores de esta Universidad y otros especialistas colaboradores, se presentan en bloques bien definidos que se distribuyen entre todos los días de programación semanal”. 


\section{La escuela en la radio}

Como se señalaba en otro momento, la apuesta de algunas emisoras de radio, especialmente las redes públicas autonómicas, por incluir en sus parrillas espacios destinados a la población infantil es otra manera de explotar las posibilidades educativas que ofrece el medio. Sin embargo, y pese a su alto valor pedagógico, en la actualidad estos programas han desaparecido prácticamente de la oferta radiofónica española, aunque algunos de ellos, como Patim, patam, patum (de la ya extinta Catalunya Cultura) y Plis Plas (de Radio Galega) lo hayan hecho recientemente.

Patim, patam, patum se emitía de lunes a viernes, de $08.00 \mathrm{~h}$. a $09.00 \mathrm{~h}$. de la mañana y de 20.00h. a 20.30h. de la tarde, así como los sábados, domingos y festivos de 09.00h. a 10.00h. de la mañana. La edición matinal de este programa se centraba a diario en una manifestación cultural distinta -cine, arte, música, teatro, libros...-, cuyos contenidos se hilvanan a partir de una entrevista a un personaje destacado del ámbito que se tratara. Además, se incluía un cuento, una sección de canciones solicitadas y un capítulo de lo que se denominaba sonidos animados, un espacio que se construía con efectos sonoros que recreaban ambientes, acciones, atmósferas, etc. Por su parte, la edición de la tarde contenía también un cuento elaborado por el equipo de dramáticos, y diversos juegos que precisaban de la participación de los niños (se planteaba adivinanzas, problemas de matemáticas, cuestiones de lógica, etc.). Las ediciones de fin de semana se confeccionaban con aquellos espacios más interesantes emitidos durante el resto de días.

Por su parte, Plis Plas, el programa infantil de la Radio Galega hasta el año 2006, se emitía todos los sábados de 09.30h. a 10.30h. de la mañana. Al igual que en el caso anterior, las distintas ediciones de Plis Plas incorporaban cuentos, música y concursos, así como un espacio denominado Os detectives verdes. Los detectives eran el inspector Pataca y su ayudante Tomatiño, dos personajes que se dedicaba a investigar sobre los males que achacan al entorno natural y, especialmente, sobre la contaminación 
ambiental. El objetivo de Os detectives verdes era formar un club de socios de defensores de la naturaleza ente la población escolar, por lo que sus productores estaban en permanente contacto con los centros de la comunidad gallega. De hecho, en enero de 2001, Os detectives habían conseguido abrir una agencia en más de 60 escuelas de Galicia, con un total de 3.000 socios.

Lo más interesante de esta experiencia radiofónica es que, para convertirse en detectives verdes, los escolares tenían que realizar en sus centros una pequeña investigación relacionada con la ecología. Los resultados de los trabajos eran explicados por los propios alumnos a través de los micrófonos de la Radio Galega y, con el fin de fidelizar a la audiencia, a los nuevos socios se les entregaba una gorra, una camiseta, un carné de detective verde homologado por la Conselleria de Medio Ambiente de la Xunta de Galicia, y un ejemplar de la revista Plis Plas.

Dadas sus características, estos programas heredaron buena parte de los objetivos y las pretensiones de aquellos otros que, en la década de los 80 (Gutiérrez, M., 1986) y principios de los 90, llegaron a conformar una oferta mucho más consistente que la que la radio nos brinda en la actualidad. Nos referimos, por ejemplo, a Peques (Radio Cadena Española); Super Baby (Radio Barcelona); Niñolandia (Radio Miramar); Amunts i Crits (Radio Nacional de España en Cataluña); Ui Avui (Catalunya Ràdio) o Cocoricocoway (Ràdio Avui). En todos estos espacios, la educación se combinaba, en mayor o menor medida, con la diversión, mediante la incorporación de secciones en las que se introducían cuentos, dramatizaciones, concursos, adivinanzas, etc. Eran, en general, programas contenedores, verdaderos cajones de sastre, en los que se intentaba utilizar la radio para despertar la imaginación entre la audiencia infantil y en los que tampoco faltaban las lecturas de poemas, la música clásica y étnica -con el fin de que la audiencia se aproximara a otras culturas-, los recorridos por lugares de interés histórico y artístico, los temas de actualidad relacionados con la naturaleza, y la información, a modo de agenda, sobre actividades de interés para los más pequeños. La participación de los escolares se fomentaba a través del teléfono, aunque en algunos casos se ofrecía la posibilidad de asistir al estudio desde el que se realizaba el espacio en directo. 


\section{Educación en comunicación audiovisual}

Junto con las experiencias vistas hasta este momento, el importante desarrollo tecnológico experimentado en los últimos años ha propiciado, igualmente, la puesta en marcha de distintas iniciativas encaminadas a trabajar la radio como uno de los ejes principales para la educación en comunicación audiovisual. En este sentido, destacan proyectos como Media Radio, impulsado por el Centro Nacional de Información y Comunicación Educativa (CNICE), un organismo dependiente del Ministerio español de Educación y Ciencia (MEC), el Xtec Ràdio, una experiencia catalana de acercamiento de la radio a la escuela que cuenta con el apoyo del Departament d'Enseyament de la Generalitat de Catalunya, y Publiradio, un recurso on-line, ideado por varios profesores del Departament de Comunicació Audiovisual i Publicitat de la Universitat Autònoma de Barcelona ${ }^{7}$, para la creación de publicidad radiofónica.

Media Radio, que se enmarca dentro de Media (Televisión, Prensa, Cine, Publicidad y Radio) es un proyecto destinado especialmente a los estudiantes de Secundaria que trata en profundidad todos los aspectos relacionados con la comunicación radiofónica. Media Radio se estructura en nueve secciones temáticas -Historia y evolución, La comunicación radiofónica, La tecnología radiofónica, La radio por dentro, ¿Cómo se hace?, La programación radiofónica, Producción de programas, Una emisora en la escuela y Pensando en la radio-, que aportan los suficientes conocimientos como para entender, comprender y experimentar con el medio y, también, para reflexionar sobre sus posibilidades informativas y expresivas. De hecho, cada una de estas secciones está plagada de imágenes fijas, de imágenes en movimiento y de sonidos que ilustran las diferentes explicaciones. Además, en algunas de ellas, se incorporan actividades interactivas que facilitan el aprendizaje.

\footnotetext{
${ }^{7}$ Publiradio es un grupo de investigación y de mejora de la calidad de la docencia constituido en el año 2002 y del que forman parte los profesores Armand Balsebre (director), José María Ricarte, Juan José Perona, David Roca, Mariluz Barbeito y Anna Fajula.
} 
Aspecto de la página principal de Media Radio

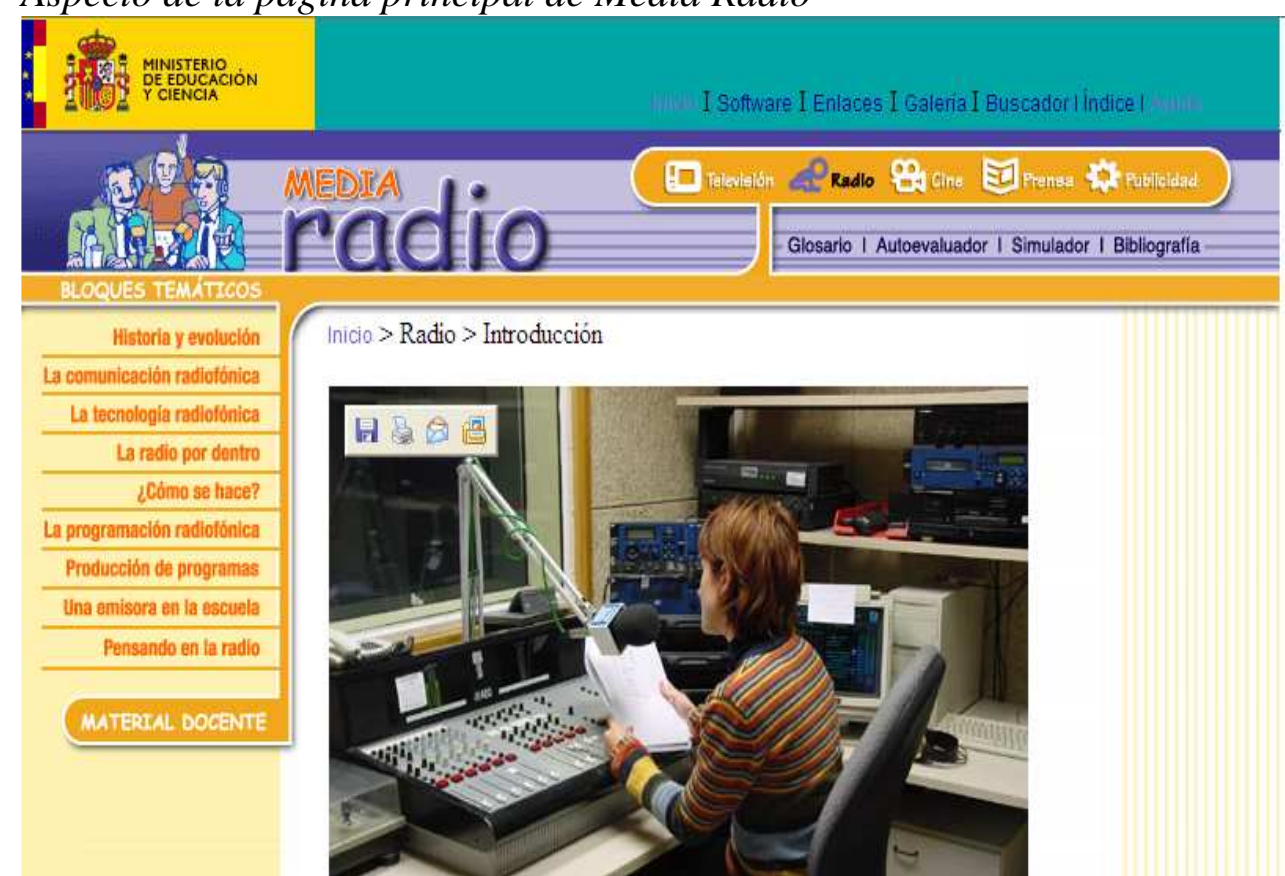

Fuente: http://recursos.cnice.mec.es/media/radio/index.html. Fecha de consulta 15-04-07

Como puede apreciarse en la parte superior de esta imagen, junto con los bloques temáticos a los que se aludía anteriormente, Media Radio cuenta con potentes herramientas complementarias, como un glosario de términos radiofónicos, un autoevaluador y una recopilación de la bibliografía más significativa, así como con un simulador para la realización de prácticas en línea. Entre estas prácticas, resultan de especial interés las de redacción, mediante las que al internauta se le propone la adecuación de textos informativos a las especiales características del medio radiofónico. 
Por su parte, el Xtec Ràdio pretende hacer de la radio un medio de comunicación escolar dentro de los centros educativos, entre los diferentes centros y su entorno. Los objetivos de este proyecto son:

-Promover el uso de la radio en todos los centros de Cataluña.

-Poner a disposición de los/las estudiantes un instrumento para fomentar el uso de la lengua hablada y escrita en general, y el catalán en particular.

-Dotar a los centros educativos de una herramienta para profundizar en el conocimiento de cómo hacer radio.

-Generar un modelo de radio de calidad como contenedor de los programas elaborados por los centros educativos.

-Difundir por Internet los espacios radiofónicos creados por niños y jóvenes.

\section{Página principal del Xtec-Ràdio}

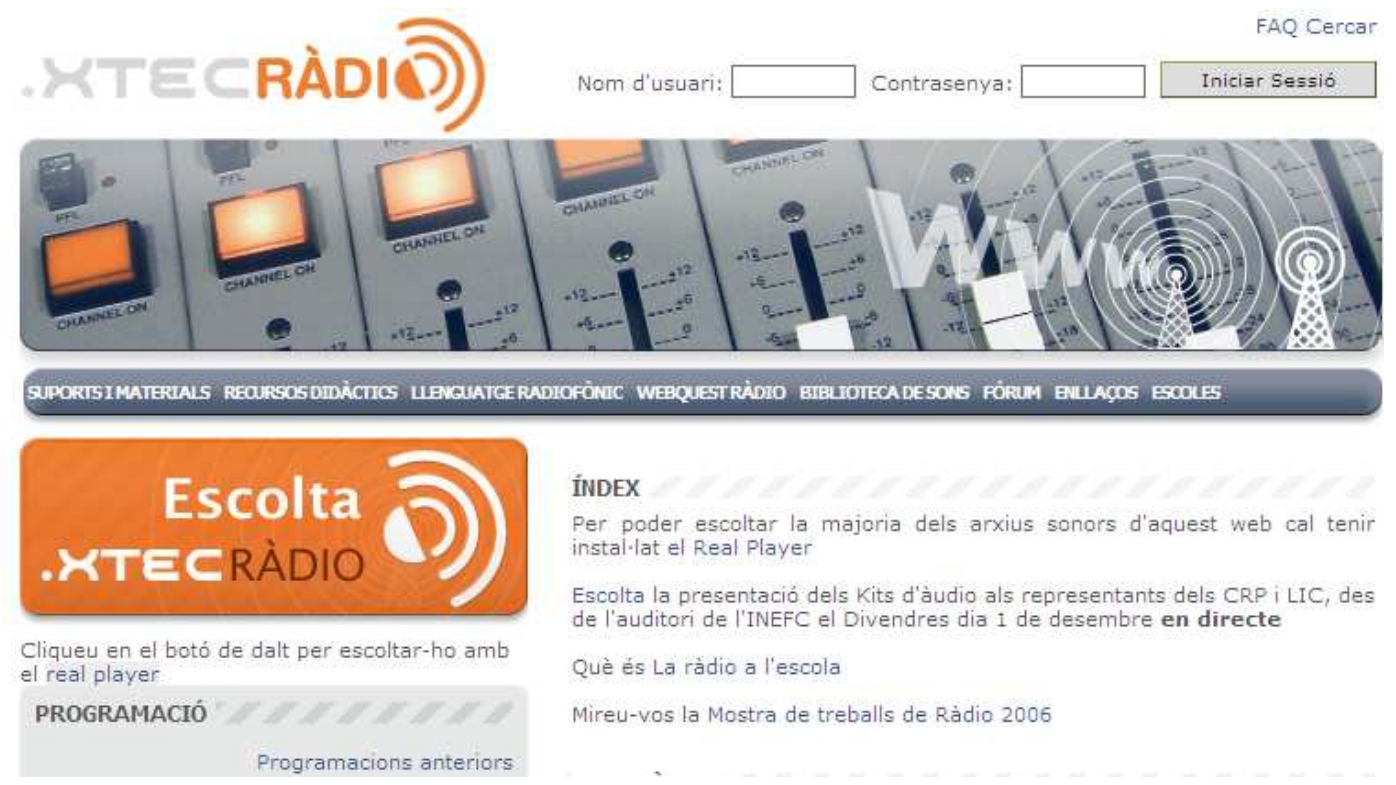

Fuente: http://phobos.xtec.cat/audiovisuals/radio/. Fecha de consulta: 15-04-07 
La barra del menú que aparece bajo la mesa de mezclas da buena cuenta de la magnitud de esta iniciativa, puesto que, entre otros, se incorporan materiales de apoyo, recursos didácticos, lecciones sobre el lenguaje radiofónico, biblioteca de sonidos, etc.

Finalmente, Publiradio (http://Publiradio.net) es un aplicativo on-line de innovación docente financiado por la Agència de Gestió d'Ajust Universitaris y de Recerca (AGAUR) de la Generalitat de Catalunya. Aunque las finalidades de dicho aplicativo son múltiples, la principal intención de sus creadores es convertirlo en una herramienta de apoyo para favorecer el trabajo autónomo, individual y grupal, de los/las estudiantes de Publicidad y Relaciones Públicas en las materias de radio, en sintonía con la nueva cultura docente derivada de la implantación del crédito ECTS y la aproximación de la Universidad española al Espacio Europeo de Educación Superior (EEES).

Aspecto de la 'Home' de 'Publiradio'

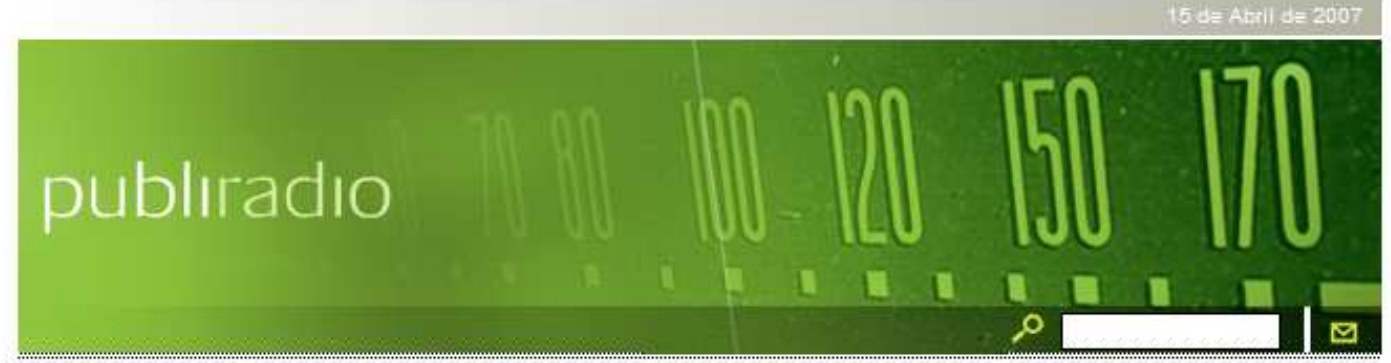

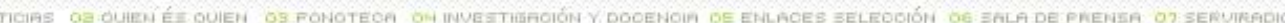

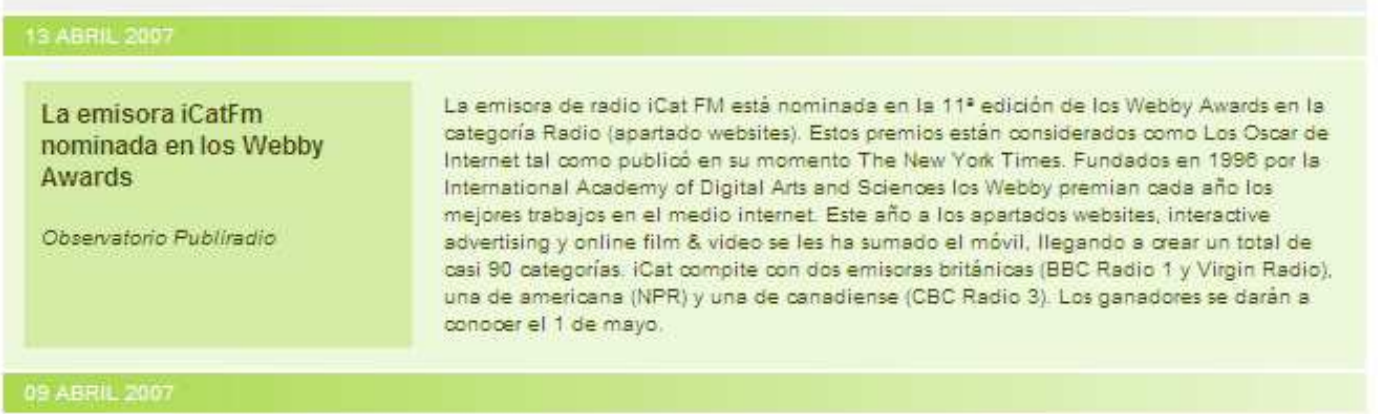




\section{Fuente: http://Publiradio.net. Fecha de consulta: 15-04-07}

Algunos de los principales objetivos de Publiradio son:

-Dar a conocer las posibilidades comunicativas de la radio en el terreno publicitario. -Abrir nueva vías de investigación que permitan superar el marco restrictivo de la descripción de problemas y pasar a la propuesta de soluciones.

-Analizar los formatos publicitarios que se utilizan actualmente en la radio y proponer nuevos recursos creativos y comunicativos.

- Contribuir a una formación universitaria más radiofónica de los futuros profesionales publicitarios, pues ellos son en definitiva los que conformarán el panorama de la publicidad radiofónica del futuro.

- Impulsar y estimular la innovación en este medio.

- Ayudar a que los diferentes actores que intervienen en el sistema publicitario español tengan un mejor conocimiento de la dimensión publicitaria de la radio.

Los contenidos de Publiradio se articulan, como se deriva de las diferentes secciones ${ }^{8}$ que lo componen, en torno a tres grandes ejes con los que se persigue (Perona, J.J., Barbeito, M.L. y Fajuja, A., 2006):

Eje 1: Conseguir que los estudiantes se familiaricen, con independencia de las explicaciones teóricas y las prácticas presenciales, con los códigos expresivos de la voz, la música, los efectos sonoros y el silencio, así como con el valor semántico de la planificación sonora y de las figuras del montaje, de manera que puedan trabajar con los componentes del lenguaje radiofónico y elaborar su propio guión de formato publicitario.

Eje 2: Aportar estrategias creativas que permitan revalorizar la eficacia de la radio como suporte de las campañas publicitarias y facilitar una base textual y sonora donde se puedan encontrar elementos útiles para llevar a cabo la realización de los formatos publicitarios radiofónicos.

\footnotetext{
${ }^{8}$ Las secciones que componen la web de Publiradio son: Noticias, Quién es Quién, Investigación y Docencia, Enlaces Selección, Sala de Prensa y Serviradio.
} 
Eje 3: Formar al alumnado para que pueda dar respuesta a la innovación profesional que, en el terreno de la publicidad radiofónica, se reclama desde múltiples sectores: anunciantes, agencias de publicidad y agencias de medios..., y neutralizar, así, la creciente pérdida de interés por la radio como medio publicitario.

Entre las secciones que conforman Publiradio, destacan, por su interés pedagógico, la Fonoteca y el Aula virtual -esta última dentro del apartado Investigación y Docencia. En la Fonoteca se pone a disposición de los estudiantes una base sonora de productos publicitarios radiofónicos, fundamentalmente cuñas -el formato por excelencia predominante en la radio-, para que conozcan la estructura, la evolución y las tendencias de la publicidad radiofónica, y se familiaricen con las estrategias creativas, no sólo actuales, sino también de otras épocas. De hecho, la Fonoteca se subdivide en tres bloques: Cuñas selección, donde se relacionan aquellas producciones publicitarias que destacan especialmente por la utilización que hacen del valor expresivo de los componentes de lenguaje radiofónico y por la estrategia creativa que presentan; Archivo Publiradio, donde se pone al alcance de todos los estudiantes y del resto de internautas todas las producciones publicitarias radiofónicas conseguidas por el equipo de trabajo; y Cuñas temporada, desde donde se pueden escuchar las cuñas que suenan en la radio actualmente o que han sonado recientemente.

En cuanto al Aula virtual, los estudiantes pueden encontrar dos tipos de elementos. Por una parte, una serie de recursos sonoros (efectos, músicas, separadores, etc.) que les permiten trabajar y desarrollar diferentes prácticas docentes programadas a lo largo del curso, ya que estos elementos sonoros facilitan el montaje radiofónico. Por otra parte, las lecciones, donde los estudiantes pueden encontrar unidades docentes que complementan el temario presencial y que están estructuradas según los principales parámetros teóricos radiofónicos: guión, lenguaje, creatividad, estructura del sistema radiodifusor, audiencias, producción, gestión, etc.

\section{Conclusión}


Las diferentes modalidades educativas de la radio que se han examinado en este artículo evidencian las numerosas posibilidades de explotación de un medio que, como demuestran las distintas experiencias analizadas, se erige como un instrumento complementario y de refuerzo de la enseñanza y el aprendizaje. Aunque algunas de estas modalidades parece haber entrado en una etapa de clara expansión, como es el caso de las radios escolares y universitarias, las cuales no han dudado en aprovechar Internet como una plataforma de difusión de los programas que realizan los centros que cuentan con emisora, otras han sucumbido ante las políticas programáticas imperantes en el sistema radiodifusor español, con operadores más preocupados por la emisión de espacios económicamente rentables que por su condición de servicio público. Esta circunstancia ha propiciado la desaparición de espacios destinados a la audiencia infantil que, dadas sus características, presentaban contenidos radiofónicos con un alto valor pedagógico.

Está demostrado que la radio fomenta el desarrollo de las capacidades imaginativas de los estudiantes, al tiempo que se revela como una herramienta transversal que puede favorecer el aprendizaje de otras materias y facilitar la interacción de los niños y los jóvenes con su entorno. Por eso, el potencial que en este sentido ofrece el medio debe ser considerado y, como bien sostiene Merayo, "en estos momentos (...), cuando los medios y la sociedad misma están cambiando vertiginosamente sin que nadie pueda predecir las consecuencias sociales de estas transformaciones, hablar de radio educativa no puede convertirse en un discurso en desuso sino, al contrario, en un reto que es preciso replantear" (Merayo, 2000). 


\section{BIBLIOGRAFÍA}

Archambault, J.P. (1998): "Internet en la escuela". En Ramonet, I. (ed.): Internet, el mundo que llega. Los nuevos caminos de la comunicación. Alianza Editorial. Madrid.

Arteaga C. et al. (2004): "La radio como medio para la educación". En Razón y Palabra. Núm. 36, México.

Barbeito, M.L. (1999): La radio galega en el ámbito rural. El caso del sur de Ourense. Trabajo de Tercer Ciclo. Multicopiado. Departamento de Comunicación Audiovisual y Publicidad. Universidad Autónoma de Barcelona

Gutiérrez, M. (1986): Los programas infantiles en la radio y televisión. Tesis doctoral. Departamento de Comunicación Audiovisual y Publicidad. Universidad Autónoma de Barcelona.

Gutiérrez, M. (1998): "La ràdio, una eina pedagògica". En Perspectiva escolar. Núm. 130. Edt. a.a.p.s.a. Rosa Sensat. Barcelona. Págs. 27-29.

Gutiérrez, M. y Huertas, A. (2003): "La programación de las radios generalistas en España”. En Zer, Revista de estudios de comunicación, núm. 15.

Moncada, A. (2000): Manipulación mediática. Educar, informar o entretener. Ediciones Libertarias-Prodhufi, S.A. Madrid.

Merayo, Arturo (2000): "Identidad, sentido y uso de la radio educativa". En Actas del III Congreso Internacional Cultura y Medios de Comunicación. Edt. Universidad Pontificia de Salamanca. Págs. 387-404.

Oliva, Mercè (2006): "Panorámica de la educación en comunicación audiovisual”. En Quaderns del Cac, núm. 25. Mayo-agosto. Barcelona. 
Perona, J.J. (1997): "Oferta programàtica". En Actes del Primer Congrès de la Ràdio a Catalunya. Edt. Societat Catalana de Comunicació. Barcelona. Págs. 145-161.

Perona, J.J. (2001): "Radio escolar en Internet: un proyecto pedagógico para la era digital”. En Red Digital. Revista de Tecnologías de la Información y Comunicación Educativas. CNICE. Núm. 1. (http://reddigital.cnice.mec.es/1/).

Perona J.J., Barbeito, M.L. y Fajula, A. (2006): "Publiradio.net: creación de un aplicativo on-line como herramienta de soporte dentro de la nueva metodología docente derivada de la implantación de los créditos ECTS". En Actes: III Jornades de Campus d'Innovació Docent. UAB. Bellaterra.

Tiffin, J. y Rajasingham, L. (1997): En busca de la clase virtual. La educación en la sociedad de la información. Edt. Paidós. Barcelona. 